\title{
Lírica y política en las hojas volantes de la imprenta de Antonio Vanegas Arroyo
}

\section{Poetry and politics in news-sheets and pamphlets from Antonio Vanegas Arroyo's printing house}

\author{
Grecia MONROY SÁNCHEZ \\ (El Colegio de San Luis) \\ grecia.monroy@gmail.com \\ ORCID ID: 0000-0002-1029-3586
}

\begin{abstract}
Within popular literature, poetry has RESUMEN. Dentro de la literatura popular, la lírica fulfilled - among many others - the function of ha tenido, entre muchas otras, la función de ser un communicating news and assessments of the actions medio de transmisión de las noticias y pareceres of rulers or the powers-that-be. This tradition, which sobre las acciones de los gobernantes o de las stems from the middle Ages, was fully developed personas en el poder. Esta tradición, que puede through the verse compositions disseminated by the remontarse a la Edad Media, tomó cuerpo en las broadsheet printed by Antonio Vanegas Arroyo in composiciones en verso que aparecieron en las hojas the Mexican early 20th century. These texts address volantes que imprimió Antonio Vanegas Arroyo en a diversity of topics and fulfill various different los albores del siglo XX mexicano. Estos textos functions within what we may call the 'poetics of líricos tienen temas diversos y ocupan diferentes news-sheets'. In this paper I shall examine the short funciones dentro de lo que puede llamarse «la poetic texts in some broadsheet appearing right after poética de la hoja volante». En esta ponencia, the armed uprising which led to the Revolution. trabajaremos con los breves textos líricos que Through their study, I shall approach the topics and aparecen en algunas hojas volantes corresponpoetic forms employed to deal with events and dientes al momento posterior al levantamiento political personalities in a revolutionary context. armado que dio inicio a la Revolución. Mediante su Also, I shall analyze how this conformed the análisis, intentaremos aproximarnos a los tópicos y Mexican popular political mindset. formas poéticas que fueron usadas para hablar de los acontecimientos y personajes políticos en un contexto revolucionario y cómo esto fue conformando el imaginario político popular de México.
\end{abstract}

KeYwords: News-sheets, Lyric, Politic, Printing PALABRAS-ClAVE: hojas volantes, lírica, política, Press, Antonio Vanegas Arroyo imprenta, Antonio Vanegas Arroyo

La imprenta de Antonio Vanegas Arroyo estuvo activa a cargo de su fundador en distintas sedes en la ciudad de México, de 1880 a 1917, funcionando después de la muerte del editor hasta 1928, como sucesión testamentaria (Castro, González y Masera, 2013: 491-492). Esos casi cuarenta años de trabajo nos dejaron un corpus amplísimo de impresos populares en los que laten igual número de respuestas que de preguntas al respecto de la cultura mexicana de principios de siglo XX.

El acervo de esa imprenta está aún a la espera de un estudio sistemático riguroso, para el cual su amplitud y heterogeneidad son todo un reto. El proyecto Impresos Populares Iberoamericanos ha hecho avances en la organización de estos impresos, tal 
como puede verse en la base de datos disponible para consulta en línea ${ }^{1}$. A partir de este trabajo de organización, ha sido posible tener un primer panorama general de la diversidad de temas y formatos presentes en este acervo e identificar un tipo específico de hojas volantes que se pueden caracterizar como político-noticiosas o históricopolíticas. En estas, conviven diferentes textos en prosa, en verso y grabados, aglutinados alrededor de un acontecimiento de alcances políticos.

Ya María Cruz García de Enterría ha señalado la larga historia de los «pliegos de cordel» que tratan temas políticos, historia que se puede remontar, de acuerdo con su rastreo, hasta el siglo XVI, con los impresos que hablaban de los acontecimientos relacionados con la monarquía reinante. En su libro Sociedad y poesía de cordel en el Barroco, en el apartado «La historia en la literatura», la investigadora afirma que: «[1]a poesía no puede permanecer al margen de los sucesos políticos y todavía menos si la poesía es popular» (García de Enterría, 1973: 50). Además, señala la importancia de estos impresos y hace un breve recuento de su evolución:

Desde los tiempos en que los Reyes Católicos encomendaban a sus poetas cortesanos esparcir por el reino todos los acontecimientos que a ellos les parecían con valor, se llega a la época en que ya no necesitan los poetas que se alimente así su vena nacional y patriótica, sino que lo hacen por propio impulso, en ocasiones ingenuo. Pero un impulso empapado de un interés político innegable y muy sensible a lo que va sucediendo día a día (García de Enterría, 1973: 50).

Esta evolución esbozada por García de Enterría es algo que puede estudiarse y ponerse a prueba a propósito de los impresos de la Vanegas Arroyo; considerando no solo los temas y referentes que tratan, sino también las formas, géneros y estructura textual de cada impreso. Lo que se expondrá aquí tiene que ver con estos últimos elementos: analizaré un par de casos de hojas volantes de la imprenta Vanegas Arroyo que tratan temas políticos mediante formas líricas, en un intento por reflexionar sobre las relaciones entre la poesía, la política y los impresos populares del México de principios de siglo XX, más específicamente, en los inicios de la Revolución Mexicana.

Ahora bien, además de lo ya mencionado por María Cruz García de Enterría, conviene tener en cuenta que las hojas volantes de tipo político-noticioso son impresos muy emparentados con composiciones encomiásticas o satíricas que, a su vez, se cruzan con otras de carácter épico y narrativo, como el corrido ${ }^{2}$. Sin embargo, aunque son géneros que pueden converger en algunos puntos, la rama de poesía política que se estudiará aquí tiene sus especificidades propias, como veremos a lo largo del análisis.

Las hojas a tratar corresponden a los años 1910 y 1911, es decir, al último año del régimen porfirista y el primero de la Revolución Mexicana. Cabe mencionar, sin embargo, que en el corpus que el Proyecto Impresos Populares Iberoamericanos ha organizado podemos encontrar un conjunto de hojas de este tipo que abarca al menos hasta el año 1916.

\footnotetext{
${ }^{1}$ Además de permitir la consulta de los impresos, la base de datos también incluye algunos textos explicativos sobre la organización que se ha realizado. En primer lugar, se distinguen cuatro formatos: hojas volantes, cuadernillos, librillos y libros. De cada uno de estos, se aventuran clasificaciones ya sean formales o temáticas o ambas. En el caso de las hojas volantes, debido a la heterogeneidad estructural presente en cada hoja, se ha optado por una clasificación temática que, aunque perfectible, es un útil punto de partida. Esta incluya las categorías: desastres, eventos públicos, histórico-político, cancionero, situaciones, juegos, divertimentos y varios. Ver: 〈http://ipm.literaturaspopulares.org/Consulta:Impresos>

${ }^{2}$ González Pérez (1999) ha analizado los corridos de algunas de las hojas volantes de Vanegas.
} 
Hay que mencionar, además, que el tema político no es exclusivo del formato de la hoja volante; pues este está presente también en el formato cuadernillo, el cual, a diferencia de la hoja, se distingue por tener una unidad temática más clara de identificar. Bajo el nombre de Colección de himnos nacionales ${ }^{3}$, lo político de estos cuadernillos se expresa en el tono patriótico e histórico de las alabanzas a los héroes de la Independencia y al acontecimiento del Centenario del año 1910. Para estas páginas, sin embargo, resulta de más interés presentar análisis de hojas volantes, pues, debido a su heterogeneidad «interna», estos impresos nos permiten aventurar ideas sobre la convivencia de formas en prosa en verso, líricas y narrativas, dentro de un mismo impreso.

Las dos hojas que elegí para analizar corresponden a dos momentos muy distintos entre sí y marcados, de hecho, por un parteaguas en la historia moderna de México: la Revolución. Además de esto, cada una de estas hojas, en sí mismas, permite ver la heterogénea estructura de su ensamblaje editorial, ya sea entre los géneros discursivos que presentan (narrativa/lírica), las formas (verso/prosa) o los tonos en el tratamiento de cierto tema.

La primera de las hojas se titula El centenario de la Independencia de México en el año de $1910^{4}$. Aunque no tiene indicada la fecha de publicación, la marca referencial en el título es suficiente para saber de qué época está hablando y cuándo se estaba distribuyendo la hoja: los meses previos, al menos, al 20 de noviembre de 1910. Esta hoja tiene un título general y dos subtítulos, cada uno de los cuales introduce una composición diferente. Ambos textos hablan de un mismo tema, el año 1910, y comparten la misma forma, el verso, pero desde dos tonos líricos distintos y con formas métricas igualmente diferentes. La primera canción se caracteriza como una «bola», popular género líriconarrativo, emparentado con el corrido. Tiene un tono solemne, hiperbólico y laudatorio de la historia mexicana; presenta coros y una métrica irregular que oscila de 5 a 8 sílabas por verso, con rima asonante. Ofrece una narrativa exaltada de la escena del levantamiento armado que dio inicio - en el imaginario popular aún hoy en nuestros días - a la Independencia de México, la madrugada del 15 de septiembre de 1810. Además de que aprovecha para «hacer algún recuerdo al general Porfirio Díaz».

Le haremos algún recuerdo
al General Porfirio Díaz
porque él ahora está gobernando
y nos da muchas garantías.

Si hoy Guerrero vieras

a nuestra Nación,

en una octaviana paz,

saldrías del sepulcro

\footnotetext{
${ }^{3}$ De estas colecciones tenemos conocimiento de dos ediciones diferentes: una de 1880 que, según se puede intuir por el índice que se anuncia en la portada, estaría dividida en tres cuadernillos de 8 páginas cada uno; y otra no fechada que integraría toda la «colección» en un sólo cuadernillo de 16 páginas. En ambos casos, los textos que — según el índice, aunque esto no se cumple cabalmente en los impresosestaban incluidos en la colección son: «Notas biográficas del cura Hidalgo», «Acta de independencia», «Himno nacional mexicano y su origen», «Himno a Hidalgo, a Morelos, a Guerrero, a Bravo y a Victoria», «Himno infantil» e «Himno a Benito Juárez». Ver registros «CHNacionalesI.djvu», «CHNacionalesII.djvu», «CHNacionalesIII.djvu» y «CHNacionalesIV.djvu» en la base de datos Impresos Populares Iberoamericanos: 〈http://ipm.literaturaspopulares.org/Inicio>

4 Disponible para consulta en la base de datos Impresos Populares Iberoamericanos: <http://ipm.literaturaspopulares.org/Índice:ECDe1910.djvu>
} 
con tu bandera en mano,

victoriando ¡libertad!

Como sucede en otras hojas, la composición poética echa mano del recurso de vincular personajes anacrónicos —en este caso, Porfirio Díaz, presidente de la época, y Vicente Guerrero, héroe de la independencia de un siglo atrás - en una misma secuencia y continuidad histórica. Por cierto que este es un rasgo fundamental en la conformación de las narrativas históricas de las naciones y se manifiesta recurrentemente en los impresos políticos de Vanegas Arroyo.

La segunda composición poética de la hoja que se está analizando se llama « 1910 !» y tiene como subtítulo «Canción a San Antonio». Presenta una estructura seriada y un tono jocoso, burlesco y de doble sentido, en el que la voz poética hace un recuento de sus amores y una petición para que en el año 1910 estos sean mejores. Veamos una estrofa:

En mil novecientos siete,

Celedonia el chicharrón

muy sabroso y muy caliente

me obsequiaba con pasión.

Como se puede ver, hay un cambio radical entre el tono solemne de la composición anterior y la jocosidad de esta. Esto se puede explicar por las posibilidades latentes de uso y de recepción de la hoja, y por el principio de «economización» que vemos en muchas de ellas: un mismo y sencillo impreso podía abarcar el espectro de funciones que oscilaba de la exaltación patriótica al canturreo de tintes alburescos. Eso sí, todo alrededor del mismo tema: el año 1910.

La segunda de las hojas que trataremos se titula Terrible temblor más de 60 víctimas y varios derrumbes en la Ciudad ${ }^{5}$, al frente, y Temblor maderista. Canción popular, a la vuelta. A diferencia de la anterior $-\mathrm{y}$ de otras tantas en las que la fecha ni siquiera figura - , esta hoja tiene una fecha editorial muy precisa: junio de 1911. Al igual que la anterior, los dos textos que la integran tratan el mismo tema, pero ahora sí con dos formas textuales distintas, verso y prosa, y con géneros diferentes.

La narración que ocupa el frente de la hoja y que se encabeza con un grabado es la crónica del temblor que ocurrió en la madrugada del miércoles 7 de junio de 1911 en la Ciudad de México. Sin embargo, esta crónica, más que periodística, llega a tener una estructura más cercana a lo lírico, por su forma anafórica al enumerar todas las muertes, con nombre y geografía, que fueron causadas por los derrumbes del temblor. Haciendo un recorrido por diversas zonas de la Ciudad de México, con un tono trágico y alarmista, teje una secuencia anafórica de derrumbe-muerte-derrumbe-muerte:

En San Lázaro se derrumbó la barda de una maderería... [...].

En la quinta calle del Dr. Navarro se derrumbó una barda causando la muerte a seis personas.

En la esquina de Jiménez y Nava se desplomó el techo [...]. $[\ldots]$.

En la casa número 8 de la calle de Victoria se desplomó la mayor parte de dicha casa

5 Disponible para consulta en la base de datos Impresos Populares Iberoamericanos: <http://ipm.literaturaspopulares.org/Página:TTCiudad_A.djvu/2> 
El trágico recuento culmina con dos párrafos «esperanzadores» y «anhelantes» que dan transición al texto que estará a la vuelta y que manifiesta, ahora sí decisivamente, el carácter político de la hoja y el giro «radical» que ha dado respecto a la que vimos anteriormente:

El luto y la desolación, que este temblor ha sembrado en multitud de familias ha venido, por desgracia a ser la nota discordante en el gran concierto de victoria, gloria y honor con que el pueblo mexicano, saludó a su egregio libertador el invicto Caudillo Don Francisco I. Madero.

¡Ojalá sea esta, la última nota negra que se tenga que registrar y sea el Epílogo, de la ya larga cadena de desgracias que ha tiempo afligen a nuestra amada patria, para la que brilla una antorcha de gloria y una era de paz y progreso.

Con esta lectura de la historia en clave de la tragedia como antecedente necesario para la paz y el progreso, la hoja da paso a una composición titulada «Temblor maderista», subtitulada como «Canción popular». Resulta muy curioso aquí como se entremezcla el afán noticioso y sensacionalista de la hoja - la narración de las muertes - con la necesidad de afirmar que la canción que se presenta ya es popular. ¿Cómo se puede definir como popular algo que recién estaba publicándose y dándose a conocer? Podríamos aventurar que esto tiene que ver con que la forma lírica así definida permitía compensar la función «noticiosa» de la hoja y, de nuevo bajo la premisa estructurante de la economización, añadir también una dimensión mítica y casi sobrenatural de los sucesos del momento y, en este caso, de la figura de Francisco I. Madero, como primer caudillo revolucionario y derrocador del régimen porfirista.

Así pues, de la misma imprenta de la que apenas meses atrás salían exaltadas canciones de elogio a Porfirio Díaz, salen ahora versos en los que se pone todo el peso del destino y de la historia en los heroicos hombros de Francisco I. Madero:

Es que a Madero el destino

lo hizo, pa presidente

y aunque se oponga Porfirio

es gloria del Continente.

Los versos de esta composición son casi todos de 8 sílabas - con excepción de algunos con largas palabras en náhuatl que parece que fueron difíciles de hacer encajar en el octosílabo. Estructuralmente, la canción ofrece una secuencia histórica que vincula los presagios funestos que los aztecas tuvieron ante la llegada de los colonizadores españoles, con el temblor que precedió — en la madrugada del 7 de junio de 1911 — la entrada triunfal de Madero a la Ciudad de México. Aunque por momentos se acerca a lo narrativo, la canción sin duda echa mano de su carácter lírico para colocar al personaje de Madero en un ámbito mítico y para tomarse ciertas licencias «poéticas» en la manera de presentar los hechos históricos.

Como curiosidad, cabe mencionar que, aunque no relacionada con F. I. Madero, hay otra hoja volante que asocia un fenómeno natural, en este caso, el paso de un cometa, con un hecho histórico; se trata de la hoja titulada El cometa del centenario de la independencia, en la cual se bautiza así a un cometa que fue visto a inicios del año 1910. Es irónico, además, que, en su parte trasera, dicha hoja incluye, como parte de una composición poética llamada «Versos del cometa», unas líneas que cantan: 
Unos decían que era indicio,

de grande revolución;

esto sí que es mentirota

en contra de la razón.

A manera de conclusiones, retomaré algunos de los aspectos planteados en los primeros párrafos de este texto, pero ahora a la luz del análisis hecho de las dos hojas. En primer lugar, cabría resaltar que una de las diferencias fundamentales entre la poesía de tipo político-noticiosa aquí estudiada y otros géneros líricos noticiosos, como el corrido, sería la relación que mantienen con la voz de la colectividad. En el caso de la poesía de las hojas políticas de Vanegas Arroyo, no resulta posible afirmar que lo ahí expresado da voz a la colectividad, pues se trata de textos que no tienen ni un origen ni un cauce puramente tradicional. En ellos, en cambio, conviven diversos géneros y formas del universo discursivo de la época. Entre los más importantes de estos, podemos mencionar: la tradición de poesía popular (que se mencionó al principio retomando a García de Enterría); la poesía épica / narrativa emparentada con el corrido; el periodismo de tipo industrial, con rasgos sensacionalistas, que se fue formando a finales del siglo XIX y principios del XX; y un discurso histórico popular, patriótico, pasional y exaltado que emerge de muchos de los procesos sociales y políticos de las naciones y que, en el caso mexicano, establece continuidades entre hitos históricos fundamentales como la Independencia y la Revolución e, incluso, la Conquista.

Así pues, en segundo lugar, podríamos decir que lo político de esta poesía no se sustenta únicamente en la manifestación de los valores de una colectividad homogénea, sino en los diversos discursos e imaginarios que conviven o están en tensión en un determinado momento. Como vimos, en una misma hoja podían presentarse formas poéticas con un mismo tema, pero tratado de maneras totalmente diferentes y con intenciones también divergentes. Además, en una comparación diacrónica de las hojas volantes, sería posible ver que hay divergencia también en cuanto al tratamiento que se le da a los mismos personajes de una hoja a otra ${ }^{6}$.

Finalmente, en tercer lugar, cabe señalar la cuestión de la relación de las formas poéticas presentes en las hojas volantes con las que aparecen en otros formatos. Como vimos, Vanegas Arroyo imprimió algunas colecciones de himnos nacionales en las que reunió textos de carácter laudatorio sobre los héroes de la Independencia. La función de esos textos estaba más cercana a la recreación de un imaginario patriótico sobre el pasado. Ahora bien, los textos poéticos de las hojas volantes, en cambio, están indudablemente determinados por el carácter noticioso del texto que acompañaban; es decir, su función era más bien la de crear el imaginario con el que se tenía que interpretar el presente.

Es por ello que los textos poéticos de las hojas volantes precisan un análisis detallado que no debe desligarse del «ensamblaje» particular de la plataforma editorial en la que se encuentran. Este ensamblaje, como ha señalado Mariana Masera, se refiere tanto a la labor que realizaba el editor y que tenía que ver con «armar» la hoja volante, disponiendo los textos e imágenes en la página, como a -me atrevo a decir- la heterogeneidad del género del impreso popular y del universo discursivo de la época que, a su vez, corresponde con la realidad social del momento.

Solo resta decir que el corpus de impresos de tema político de la imprenta de Antonio Vanegas Arroyo ofrece un material indispensable que puede aportar no solo a la

\footnotetext{
${ }^{6}$ Este tema lo he desarrollado ampliamente para otro conjunto de hojas de tipo político noticioso de la imprenta de Vanegas Arroyo en Monroy Sánchez (2018).
} 
definición de las características de la poesía popular de tema político que circulaba en el México de entre siglos, sino también a la comprensión de los imaginarios con los que la sociedad del momento interpretaba y recreaba su realidad; muchos de los cuales, de hecho, son imaginarios que sigan vivos hoy en día.

\section{BIBLIOGRAFÍA}

Base de datos Impresos Populares Iberoamericanos.

URL: 〈http://ipm.literaturaspopulares.org/Inicio>

CASTRo PÉrez, Briseida, GonZÁlez Bolívar, Rafael y MASERA, Mariana (2013): «La Imprenta Vanegas Arroyo, perfil de un archivo familiar camino a la digitalización y el acceso público: cuadernillos, hojas volantes y libros», Revista de Literaturas Populares, Año XIII, 2, julio-diciembre, pp. 491-503.

García DE EnTERríA, María Cruz (1973): Sociedad y poesía de cordel en el Barroco, Madrid, Taurus.

GonZÁlez PÉREZ, Aurelio (1999): «Caracterización de los héroes en los corridos mexicanos», Caravelle. Héros et nation en Amérique Latine, 72, pp. 83-97. DOI: https://doi.org/10.3406/carav.1999.2836

MONROY SÁNCHEZ, Grecia (2018): «Literatura, periodismo e historia popular: las hojas volantes histórico políticas de la imprenta Vanegas Arroyo (1910-1912)» en Mariana Masera (coord.), Notable suceso: ensayos sobre impresos populares. El caso de la imprenta Vanegas Arroyo, México, UNAM.

Fecha de recepción: 24 de abril de 2019

Fecha de aceptación: 1 de septiembre de 2019

$$
\text { j }
$$

